\title{
Kinetic Study of Agricultural Wastes Conversion to Biogas using Cow Dung/Poultry Droppings as Inoculums
}

\author{
Tsunatu D. Yavini ${ }^{1}$, Kiman Silas ${ }^{2}$, Mustapha B. Grema ${ }^{2}$ and Jang A. Luria ${ }^{1}$ \\ 1. Chemistry Department, Taraba State University, P.M.B 1167, Jalingo - Taraba State \\ 2. Chemical Engineering Department, University of Maiduguri, Maiduguri - Borno State
}

\begin{abstract}
Anaerobic Digestion of agricultural wastes; animal wastes, energy crops and industrial wastes is a technology that produces biogas (Methane Rich Gas), a promising source of energy which is renewable as well as eco-friendly. This study was designed to determine the kinetics of agricultural wastes biogas production when inoculated with cow dung/poultry droppings under mesophilic conditions with 8\% Total Solids and 55 days retention time. The modified first order kinetic model was developed to access the kinetics of the biodegradation of the digestion process. A plot of $1 / t(\ln (d y t / d t))$ against $1 / t$ from the model gives the rates of substrate biodegradability and removal of the biodegradable fractions of the substrate. The result shows that maize cobs $(M C)$ has the highest short term biodegradability index of 1.5827 while bio-digester $D(S B)$ has the lowest rate of the biodegradable fractions ( $k$ ) of - 0.302 among all the substrates. Bio-digester C (Rice Straw) has the highest yield of biogas with cumulative volume of $692.9 \mathrm{ml}$ and an $R^{2}$ value of 0.8424 while bio-digester $D$ (Sugarcane Bagasse) has the least of $185.9 \mathrm{ml}$ and an $R^{2}$ value of 0.6479 .
\end{abstract}

Keywords: Anaerobic Digestion, Mesophilic, Kinetic, Biogas, Biodegradability, Agro-wastes.

\section{Introduction}

The quest to find an alternative source of fuel to replace the fast depleting fossil fuel prompted the discovery and use of biogas, a renewable energy which plays very important role in the reduction of greenhouse gas, reduces nitrogen and odour from manure management, and intensifies the recycling of nutrients within agriculture in the form of bio-fertilizers (Fantozzi and Buratti, 2009; Salman, 2013).

Biogas is a commonly used biofuel around the globe and is generated through an environmental friendly process of anaerobic digestion or the fermentation of biodegradable matters such as biomass, manure, sewage, municipal waste, rubbish dumps, septic tank, green waste and energy crops with a stable product (soil conditioner) for agricultural purposes without any detrimental effect on the environment (Salman, 2013 ; Jagadish et al, 2012).

The actual composition of biogas will vary depending upon origin of the anaerobic digestion process i.e. the feedstock, with Stiffen et al (2000) stating that, it comprises of methane, $\mathrm{CH}_{4}(55-75 \%)$ and carbon dioxide $\mathrm{CO}_{2}\left(25-45 \%\right.$ ) with a reported calorific value of $20 \mathrm{MJ} / \mathrm{m}^{3}$ (Yusuf et al, 2011 ; Membere et al, 2012 and Nuhu et al, 2013).

Agricultural residues are fast growing wastes widely distributed throughout the world. These materials keep increasing as agricultural activities keeps increasing across the globe in search of food to curtail the recent food crisis. These wastes when not properly harnessed pose series of problems which ranges from environmental pollution, alteration of water chemistry and depletion of dissolved oxygen when deposited in water bodies, and to some extent causes diseases to many municipalities, as can be seen constituting $30 \%$ of the total organic composition of Jalingo metropolis, a typical example (Tsunatu and Abdullahi, 2013). Therefore, attempts have been made by various researchers in the search of ways of reducing the accumulation and spread of these wastes either through biological, chemical and mechanical means with much attention focused on biological approach through anaerobic digestion to produce biogas (Salman, 2013 ; Stewart et al, 1984).

The main problem with anaerobic digestion of crop residues is that most of the agricultural residues are lignocellulosic with low nitrogen content. To improve the digestibility of these crop residues, pre-treatment methods like size reduction, electron irradiation, heat treatment, enzymatic action are necessary (Gamma'a et al, 2006). For optimizing the $\mathrm{C}: \mathrm{N}$ ratio of agricultural residues, co-digestion with sewage sludge, animal manure or poultry litter is highly recommended (Hills, 1980).

This research work presents the study of anaerobic digestion of various agricultural wastes such as Groundnut Shell [GS], Maize Cob [MC], Rice Straw [RS] and Sugarcane Bagasse [SB] inoculated with a mixture of cow dung/poultry droppings was studied. The result obtained were further used to determine the best substrate for biogas generation and comparing the actual generation with the first order kinetic equation that describes the biodegradability of the anaerobic digestion process. 


\section{Substrate Collection:}

\section{Materials And Methods}

Raw materials used for the study were obtained as follows; Groundnut Shell was obtained from a Sheller in Sabon-gida Tukura, Gassol L.G.A, Maize cobs used was from a household maize thresher in Jalingo metropolis, Rice Straw was collected from a rice farm at Jauro-Yinu along Jalingo-Wukari Road, Sugarcane Bagasse was collected from the piles deposited by cane sellers around the A.T.C junction of the Taraba State University axis. Overnight, fresh poultry droppings was collected from a domestic poultry house at University staff quarters, TSU-B28 and fresh cow dung was obtained from the Animal Science Department farm, TSUJalingo.

\section{Experimental Set-Up}

Set of bio-digesters were labeled (A - D) each containing an agricultural waste (Sample A: GS, Sample B: MC, Sample C: RS and Sample D: SB) inoculated with cow dung/poultry droppings as starter with its volume kept at approximately $10 \%$ (v/v) of the reactant volume as described by (Eltawil and Belal, 2009). Recommended water content was determined for each sample as reported by (Ituen et al, 2007). i.e. a total solid of $7-10 \%$ in the fermentation slurry was considered. $27 \mathrm{~g}$ of the substrates was charged into each of the batch reactors and were maintained at a temperature range between $33-35^{\circ} \mathrm{C}$ and the appropriate quantity of water was added. The bio-digesters were set-up as described by (Itodo et al, 1992 and Membere et al, 2012) and the biogas measurement was carried out by using the water displacement method in which the volume of the saturated acidified saline water displaced was proportional to the volume of biogas generated. The acidified saturated salt solution was to prevent the dissolution of $\mathrm{CO}_{2}$ contained in the biogas at atmospheric pressure.

\section{Solids Analysis}

Total Solid (TS) and Volatile Matter (VM) were analyzed for the substrates GS, MC, RS and SB according to standard methods (APHA, AWWA and WPCF, "Standard Methods for the Examination of Water and Wastewater" 20, Washington, D.C., 1998). Table 1 gives the solid analysis, $\mathrm{P}^{\mathrm{H}}$ and Temperatures of these substrates. Total Solids (TS) are the sum of suspended solids and dissolved solids. The Total Solids are composed of two components, Volatile Matter (VM) and Fixed Solids. The VM are organic portion of TS that biodegrade anaerobically. These parameters are calculated using equations (1) and (2) (Jagadish et al, 2012).

$$
\begin{gathered}
\operatorname{TS}(\%)=\frac{(A-B)}{(D-B)} \times 100 \\
V M(\%)=\frac{(A-C)}{(A-B)} \times 100
\end{gathered}
$$

Where:

$$
\begin{aligned}
& A=\text { weight of dish }+ \text { dried sample at } 75^{\circ} \mathrm{C}(\mathrm{g}) \\
& B=\text { weight of dish }(\mathrm{g}) \\
& C=\text { weight of dish }+ \text { Sample after ignition at } 550^{\circ} \mathrm{C}(\mathrm{g}) \\
& \mathrm{D}=\text { weight of dish }+ \text { wet sample }(\mathrm{g})
\end{aligned}
$$

Table 1: Solid Analysis and $\mathrm{P}^{\mathrm{H}}$ Data for the various Substrates

\begin{tabular}{|c|c|c|c|c|}
\hline Digester & TS(\%) & VM(\%) & $\mathbf{P}^{\mathbf{H}}$ & Temperature $\left({ }^{\mathbf{0}} \mathbf{C}\right)$ \\
\hline Sample A & 92.00 & 82.96 & 7.6 & 33 \\
Sample B & 84.38 & 77.78 & 7.2 & 35 \\
Sample C & 94.43 & 81.48 & 7.5 & 33.5 \\
Sample D & 87.10 & 85.19 & 6.9 & 33 \\
\hline
\end{tabular}

Table 2: Cumulative Biogas Yield of the various Substrates per Volatile Matter (VM)

\begin{tabular}{|c|c|c|c|c|}
\hline \multirow{2}{*}{ Time (Days) } & \multicolumn{4}{|c|}{ Cumulative Biogas Production (ml/g VM) } \\
\cline { 2 - 5 } & GS & MC & RS & SB \\
\hline 0 & 0 & 0 & 0 & 0 \\
5 & 0.49 & 0.82 & 1.80 & 0.14 \\
10 & 2.56 & 3.14 & 4.82 & 1.23 \\
15 & 5.04 & 6.27 & 8.60 & 4.05 \\
20 & 8.87 & 9.92 & 12.67 & 6.74 \\
25 & 11.92 & 13.83 & 18.00 & 7.27 \\
30 & 13.61 & 17.46 & 21.80 & 7.84 \\
35 & 14.19 & 20.15 & 24.66 & 8.08 \\
40 & 14.53 & 21.40 & 26.84 & - \\
45 & - & 22.32 & 28.68 & - \\
50 & - & - & 30.13 & - \\
55 & - & - & 31.50 & - \\
\hline
\end{tabular}




\section{Results And Discussions}

\section{Kinetic Modeling of the Bio-digesters at Mesophilic Conditions}

This study assessed the substrate biodegradability by developing a mathematical model that was based on the first order kinetics for bio-digesters operating as batch systems (Yusuf et al, 2011). The entire kinetic is described by equations ( 3 - 7) for a batch reactor system.

$$
\frac{y_{m}}{\left(y_{m}-y_{t}\right)}=\frac{C_{o}}{C_{t}}
$$

Where:

$\mathrm{C}_{\mathrm{o}}=$ Is the initial Volatile Solids

$\mathrm{C}_{\mathrm{t}}=$ represents the Volatile Solids Concentration at time $(\mathrm{t})$, which is given by:

$$
\begin{aligned}
& \ln \left[\frac{C_{t}}{C_{o}}\right]=-k t \quad \text { Or } \\
& \ln \left[\frac{C_{o}}{C_{t}}\right]=k t
\end{aligned}
$$

Substituting $\frac{C_{o}}{c_{t}}$ in Eq. (4) with $\frac{y_{m}}{\left(y_{m}-y_{t}\right)}$ yields;

Where:

$$
\begin{gathered}
{\left[\frac{y_{m}-y_{t}}{y_{m}}\right]=\exp ^{(k t)}} \\
y_{m}\left[1-\exp ^{(k t)}\right]=y_{t}
\end{gathered}
$$

$y_{t}=$ Volume of biogas produced per unit mass of VM fed at any time ( $\left.\mathrm{t}\right)$

$y_{m}=$ Volume of biogas per unit mass of VM converted at maximum time.

The rate constant associated with the degradation of the biodegradable fractions is represented by $\boldsymbol{k}$ (1/days), while the period of digestion is represented by $\boldsymbol{t}$ (days).

Attempting to linearize Eq. (6) by differentiating it, we obtain,

$$
\frac{d y_{t}}{d t}=y_{m} k \exp ^{(k t)}
$$

Taking natural logarithm on both sides,

$$
\ln \left(\frac{d y_{t}}{d t}\right)=\left(\ln y_{m}+\ln k\right)-k t
$$

This equation can be reduced to the form;

$$
\frac{1}{t} \ln \left(\frac{d y_{t}}{d t}\right)=\frac{1}{t}\left(\ln y_{m}+\ln k\right)-k
$$

Equation (9) is analogous to the straight line equation $y=m x+c$, in which $\left(\ln y_{m}+\ln k\right)$ represents the slope and, $(-k)$ represents the intercept of the graph, when $\frac{1}{t} \ln \left(\frac{d y_{t}\left(\frac{m l}{g V M}\right)}{d t(d a y)}\right)$ is plotted against $\frac{1}{t}\left(\frac{1}{\text { day }}\right)$.

The term $\left(\ln y_{m}+\ln k\right)$, slope is a measure of the availability of readily and moderately degradable fractions of the substrate. This term can frequently be used to select substrate with the potential for high biogas production from a given substrate volatile solid under short retention time. Higher values shows the potentials of production of high biogas quantity while lower values signifies the ability of the substrates to produce low quantity of biogas under short retention periods from a given substrate volatile solids (Godley et al, 2003).

The value of $(k)$ is the measure of the rate of removal of the biodegradable fractions as the biogas yield increases with time. The more negative the value of $(k)$, the faster the rates of removal of the biodegradable fractions while the more positive the value of $(k)$, the slower the rate of removal of the biodegradable fractions. 
These two parameters (room temperature short term biodegradability and removal rates of biodegradable fractions) of the substrates used in the anaerobic digestion are presented in Figure $3-6$.

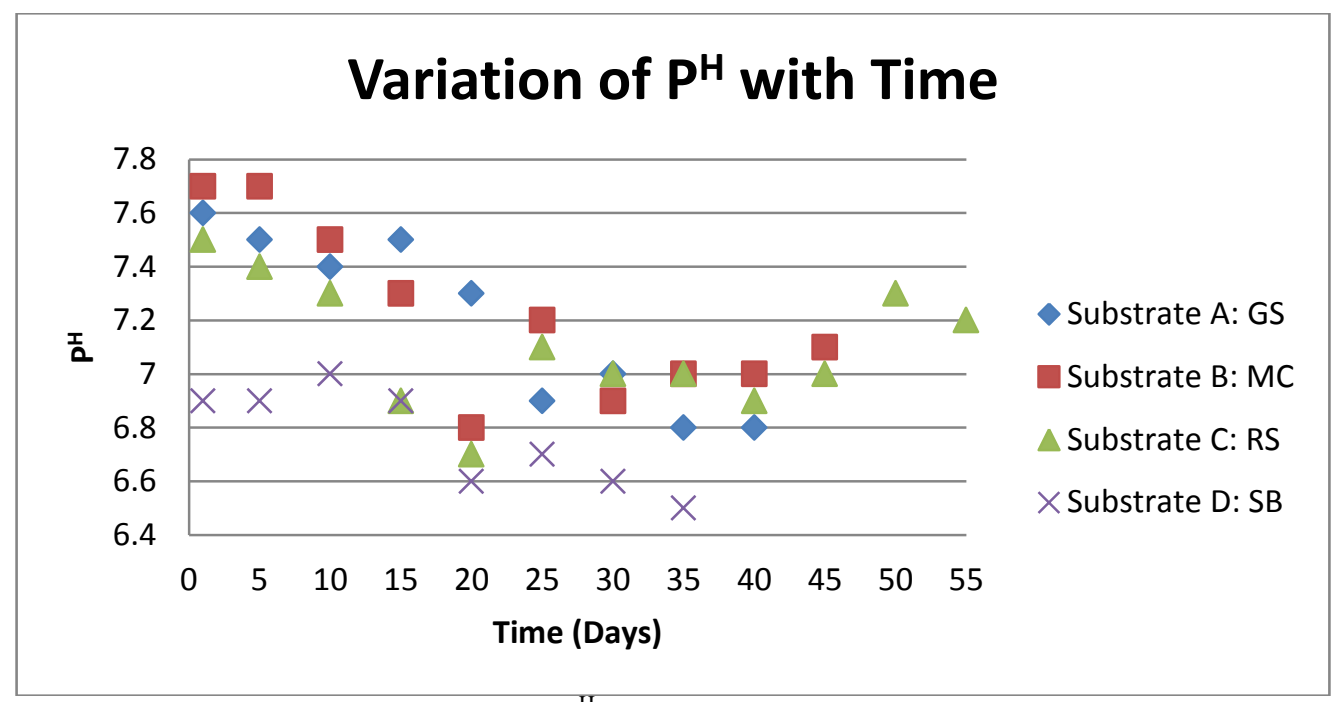

Figure 1: Variation of $\mathrm{P}^{\mathrm{H}}$ with Time of the various Substrates

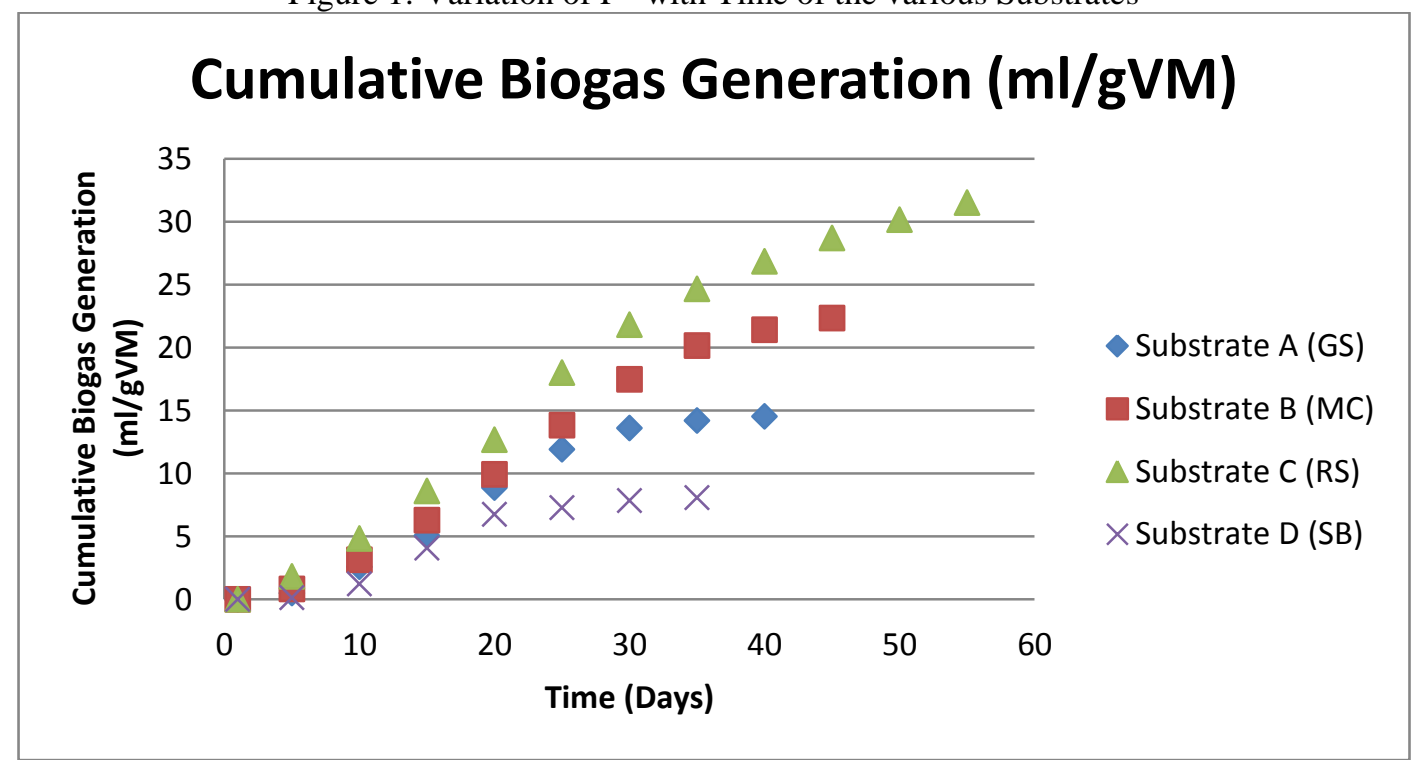

Figure 2: Cumulative Biogas Generation (ml/g VM) with Time of the various Substrates

From Figure (3 - 6), the room temperature short term biodegradability of the substrate in the bio-digester A for the period under study was observed to be 1.3092 while the removal rate constant of biodegradable fractions was established to be -0.4530 . The model was able to fit the data set with goodness of fit $\left(\mathrm{R}^{2}\right)$ of 0.7484 . Similarly, bio-digester B,C and D had room temperature short term biodegradability of 1.5827, 1.5334 and 0.9157 ; removal rate constant of biodegradable fractions of $-0.5677,-0.7002$ and -0.302 ; and $\mathrm{R}^{2}$ values of $0.8274,0.8424$ and 0.6479 respectively.

Substrate in bio-digester B, had the highest value (1.5827) of room temperature short term biodegradability, signifying it had the highest potential to produce more quantity of biogas for a given substrate volatile solid, followed by substrates in bio-digester C, A and D. Substrate in bio-digester D, had the lowest removal rate constant $(k)$ value of -0.302 as can be seen in Figure 2 that this same bio-digester D had the lowest value of biogas generated. This could be attributed to the optimum $\mathrm{C}: \mathrm{N}$ ratio in this bio-digester. The linear polynomial was able to fit the experimental data as shown in the Figures $3-6$. 


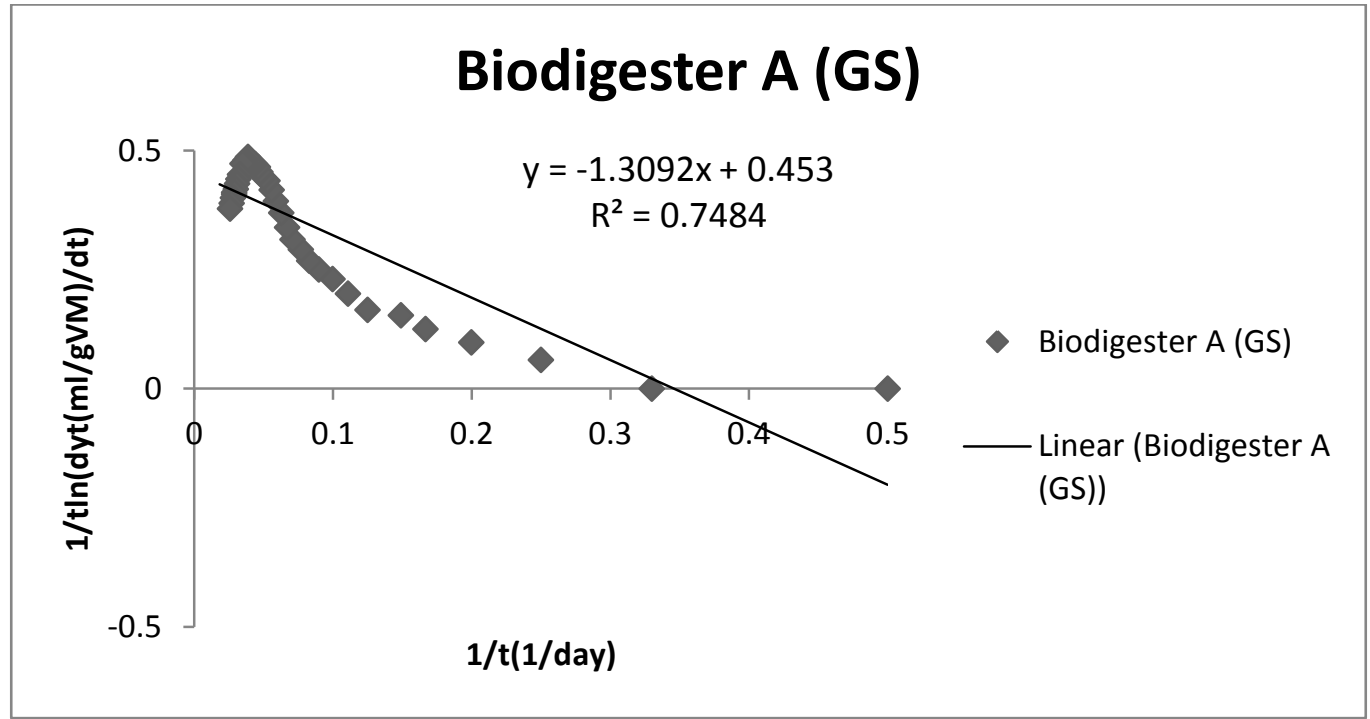

Figure 3: Plot of 1/t $(\ln (\operatorname{dyt}(\mathrm{ml} / \mathrm{gVM}) / \mathrm{dt}))$ against 1/t for Bio-digester A

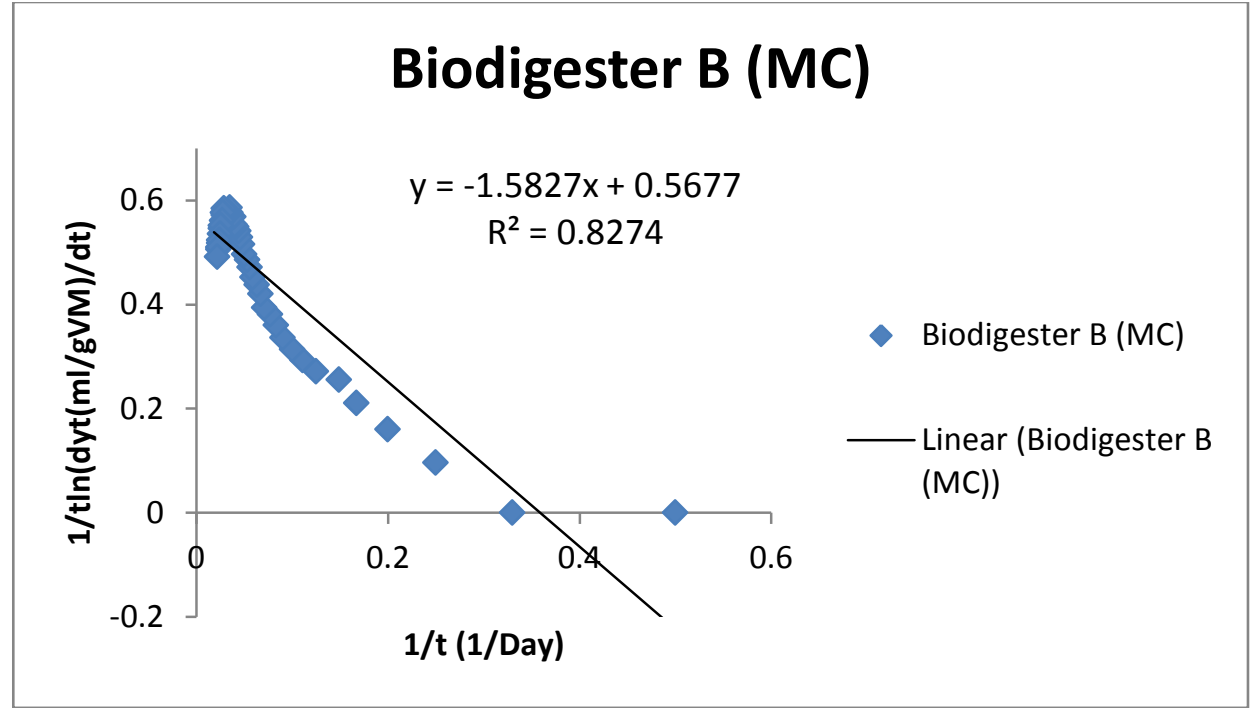

Figure 4: Plot of 1/t(ln(dyt(ml/gVM)/dt ) ) against 1/t for Bio-digester B

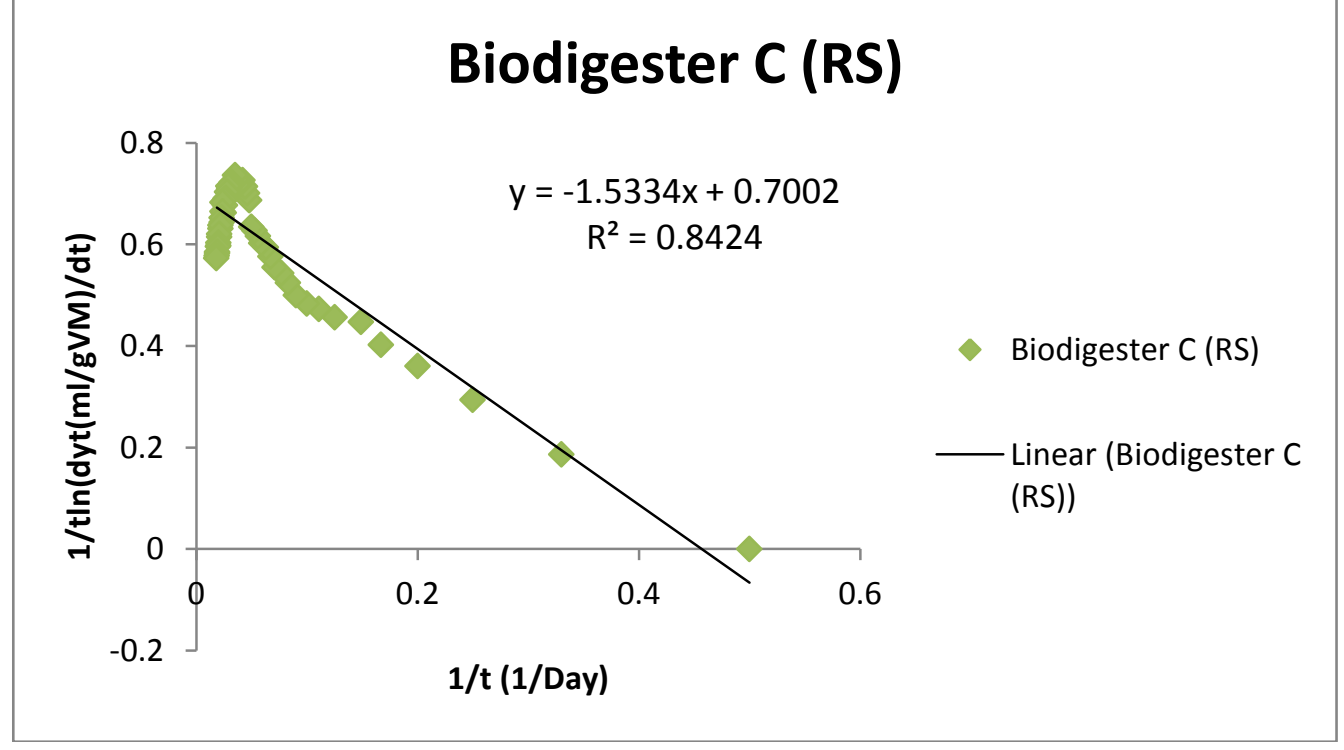

Figure 5: Plot of 1/t $(\ln (\operatorname{dyt}(\mathrm{ml} / \mathrm{gVM}) / \mathrm{dt}))$ against 1/t for Bio-digester C 


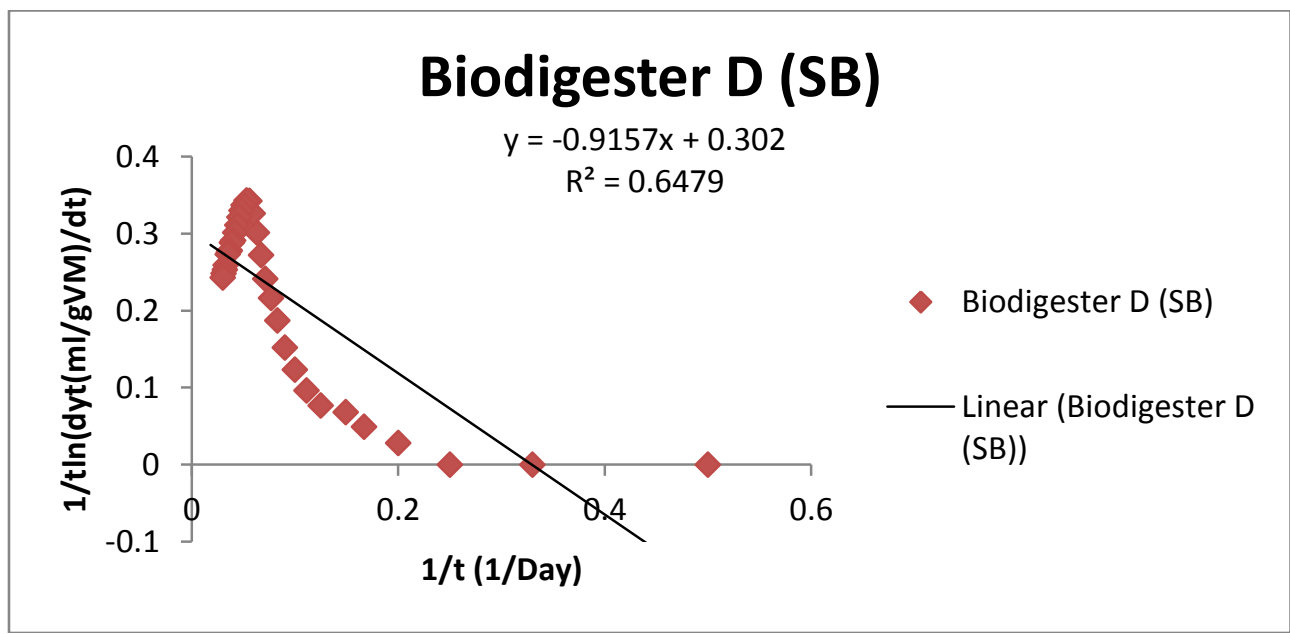

Figure 6: Plot of 1/t $(\ln (\mathrm{dyt}(\mathrm{ml} / \mathrm{gVM}) / \mathrm{dt}))$ against $1 / \mathrm{t}$ for Bio-digester $\mathrm{D}$

\section{Conclusion}

Biogas production from agricultural wastes (Groundnut Shell, Maize Cobs, Rice Straw and Sugarcane Bagasse) inoculated with cow dung/poultry droppings was established in this research work to be feasible at room temperature. This gives positive attribute towards a search for Sustainable Renewable Energy Source (SRES) to substitute the fast depleting fossil fuels. The best performance of biogas generated was observed in bio-digester $\mathrm{C}$, subsequently followed by $\mathrm{B}, \mathrm{A}$ and $\mathrm{D}(\mathrm{C}>\mathrm{B}>\mathrm{A}>\mathrm{D})$, Figure 2 . To ascertain this result, the observation made was corroborated using a modified first - order kinetic model. This model best describes the cumulative biogas produced as a function of time. With bio-digester B having the highest room temperature short term biodegradability index of 1.5827 and bio-digester $\mathrm{D}$ with the lowest removal rate constant of -0.302 . Successful implementation of this technology will create a stabilized resource that retained the bio-fertilizer value of original material and reducing unwanted pathogens and improved public health.

\section{Reference}

[1]. APHA (1998): Standard Methods for the Examination of Water and Wastewater. $20^{\text {th }}$ Edition. APHA, AWNA, Washington D.C.

[2]. Eltawil, M.A and Belal, E.B.A (2009) "Evaluation and Scrubbing of Biogas Generation from Agricultural Wastes and Water Hyacinth” Biological Engineering. Misr Journal Ag. Eng.,26(1). Pp. 534 - 560

[3]. Fantozzi, F., and Buratti, C. (2009) "Biogas Production from different Substrates in an Experimental Continuously Stirred Tank Reactor Anaerobic Digester". Bioresource Technology, Vol. 100, pp. 5783 - 5789

[4]. Gamma'a, A.O., El-Tinay, A.H., and El-Yamen, F.M. (2006) "Biogas Production from Agricultural Wastes". Journal of Food Technology 4(1): pp. $37-39$.

[5]. Godley, A., Lewin, K., and Graham, A. (2003) "Estimating Biodegradable Municipal Solid Waste Diversion from Landfill". [Assessed 14 ${ }^{\text {th }}$ December, 2013]

[6]. Hills, D.J. (1980) "Biogas from a High Solid Combination of Dairy Manure and Barely Straw" Transaction - ASAE, 23: pp. 1500 1504

[7]. Itodo, I.N., Lucas, E.B., and Kucha, E.L. (1992) "The Effect of Media Material and its Quality on Biogas Yield". Nigeria Journal of Renewable Energy, 3. Pp. 45 - 49.

[8]. Ituen, E.E., John, M.M., and Bassey, B.E. (2007) "Biogas Production from Organic Waste in Akwa Ibom State of Nigeria. Appropriate Technologies for Environmental Protection in the Developing World. Selected Papers from ERTEP 2007, July 17 -19, Ghana.

[9]. Jagadish, H., Malourdu, A.R., Muralidhara, P.L., Desai, S.M., and Mahadeva, G.K. (2012) "Kinetics of Anaerobic Digestion of Water Hycinth using Poultry Litter as Inoculums". International Journal of Environmental Science and Development, 3. Pp. 2

[10]. Membere, E.A., Ugbebor, J., and Akan, U.E. (2012) "Biomechanization Potential of Organic Fraction of Municipal Solid Waste from Co-digestion of Pig and Cow Dung”. International Journal of Environmental Science (IJNS), 2(4), pp. 2387 - 2399.

[11]. Membere, E.A., Ugbebor, J., and Akan, U.E. (2012) "Biomechanization Potential of Organic Fraction of Municipal Solid Waste from Co-digestion of Pig and Cow Dung”. International Journal of Environmental Science (IJNS), 2(4), pp. 2387 - 2399.

[12]. Nuhu, M., Mujahid, M.M., Aminu, A.H., Abbas, A.J., Babangida, D., Tsunatu, D.Y., Aminu, Y.Z., Mustapha, Y., Ahmed, I., and Onukak, I.E. (2013) “Optimum Design Parameter Determination of Biogas Digester using Human Faeces Feedstock". Journal of Chemical Engineering and Materials Science (JCEMS); Academic Journals. Vol. 4(4): pp. 46 -49

[13]. Salman, Z. (2013) "Biogas from Agricultural Wastes, BioEnergy Consult. www.bioenergyconsult.com/anaerobic-digestion-cropresidues/. Accessed: 29/12/2013.

[14]. Stewart, D.J., Bogue, M.J. and Badger, D.M. (1984) "Biogas Production from Crops and Organic Wastes" New Zealand. J. Sci. 27: $285-294$.

[15]. Stiffen, R., Szolar, O., and Braun, R. (2000) "Feedstock for Anaerobic Digestion, Making Energy and Solving Modern Waste Problems"' (Internet), AD-Nett. Available from www.adnett.org/dl feedstocks.pdf. [Accessed on 16 ${ }^{\text {th }}$ December, 2013]

[16]. Tsunatu, D.Y. and Abdullahi, A.M. (2013) "Municipal Solid Waste and Pollution Management in Jalingo Metropolis: Problems, Challenges and Strategies". Journal of Environment. Scientific Journal. Vol.2, Issue 5, pp. 125 - 133.

[17]. Yusuf, M.O.L., Debora, A., and Ogheneruona, D.E. (2011) "Ambient Temperature Kinetic Assessment of Biogas Production from Co-digestion of Horse and Cow Dung”. Res. Agr. Eng. 57(3), pp. 97 - 104 